\title{
Adsorption isotherms, kinetics, thermodynamics and desorption studies of 2,4,6-trichlorophenol on oil palm empty fruit bunch-based activated carbon
}

\author{
I.A.W. Tan, A.L. Ahmad, B.H. Hameed* \\ School of Chemical Engineering, Universiti Sains Malaysia, Engineering Campus, 14300 Nibong Tebal, Penang, Malaysia
}

\section{A R T I C L E I N F O}

\section{Article history:}

Received 16 May 2008

Received in revised form 8 August 2008

Accepted 11 August 2008

Available online 19 August 2008

\section{Keywords:}

Oil palm empty fruit bunch activated

carbon

2,4,6-Trichlorophenol

Isotherm

Kinetics

Desorption

\begin{abstract}
A B S T R A C T
The adsorption characteristics of 2,4,6-trichlorophenol (TCP) on activated carbon prepared from oil palm empty fruit bunch (EFB) were evaluated. The effects of TCP initial concentration, agitation time, solution pH and temperature on TCP adsorption were investigated. TCP adsorption uptake was found to increase with increase in initial concentration, agitation time and solution temperature whereas adsorption of TCP was more favourable at acidic $\mathrm{pH}$. The adsorption equilibrium data were best represented by the Freundlich and Redlich-Peterson isotherms. The adsorption kinetics was found to follow the pseudo-second-order kinetic model. The mechanism of the adsorption process was determined from the intraparticle diffusion model. Boyd plot revealed that the adsorption of TCP on the activated carbon was mainly governed by particle diffusion. Thermodynamic parameters such as standard enthalpy $\left(\Delta H^{\circ}\right)$, standard entropy $\left(\Delta S^{\circ}\right)$, standard free energy $\left(\Delta G^{\circ}\right)$ and activation energy were determined. The regeneration efficiency of the spent activated carbon was high, with TCP desorption of $99.6 \%$.
\end{abstract}

(c) 2008 Elsevier B.V. All rights reserved.

\section{Introduction}

Cholorophenols are a group of chemicals in which chlorines (between one and five) have been added to phenol. The main pollution sources containing chlorophenols are the wastewaters from pesticide, paint, pharmaceutics, wood, paper and pulp industries as well as water disinfecting process [1]. Chlorophenols are weak acids which permeate human skin by in vitro and are readily absorbed by gastro-intestinal tract [2]. 2,4,6-Trichlorophenol (TCP) is a toxic, mutagenic and carcinogenic pollutant. It is found in the emissions from fossil fuel combustion, municipal waste incineration and chlorination of water containing phenol or certain aromatic acids with hypochlorite or during disinfection of water [3]. TCP has been also reported to cause adverse effects on human nervous system and respiratory problems such as chronic bronchitis, cough and altered pulmonary function [4]. The stable $\mathrm{C}-\mathrm{Cl}$ bond and the position of chlorine atoms relative to the hydroxyl group are responsible for their toxicity and persistence in the biological environment [5]. Due to its high toxicity, carcinogenic properties, structural stabilization and persistence in the environment, the removal of TCP from the environment is crucial.

From the literature, various treatment methods have been applied to remove phenolic compounds from aqueous solutions,

\footnotetext{
* Corresponding author. Fax: +60 45941013.

E-mail address: chbassim@eng.usm.my (B.H. Hameed).
}

such as biological treatment using anaerobic granular sludge [1], catalytic wet oxidation [3], photochemical treatment [6], adsorption technology using activated clay [4], fuel oil fly ash [7] and activated carbons prepared from various precursors such as rattan sawdust, coconut shell and rice straw [8-10]. Other treatment technologies include air stripping, incineration, ion exchange and solvent extraction [4]. Adsorption on activated carbon is one of the most effective and widely used techniques in treating high strength and low volume of phenolic wastewaters [2]. Commercially available activated carbons like F300 granular activated carbons from Calgon Corp, Pittsburgh, PA are commonly used for the adsorption of chlorophenols [11]. However, the usage of activated carbon has been limited by its high cost due to the use of non-renewable and relatively expensive starting material such as coal, which is a major economic consideration [12]. This has prompted a growing research interest in the production of low cost activated carbons especially for application concerning wastewater treatment.

Recently, focus has been given on the preparation of activated carbons from agricultural by-products such as almond shell [13], bean pod [14], rice husk [15], cherry stone [16], date palm seed [17], sunflower seed hull [18], waste apricot [19], oil palm fibre [20], bamboo [21], plum kernel [22] and coconut husk [23,24]. Besides, not many studies have been reported in the literature on the adsorption of TCP using agricultural waste-based activated carbon. In practice, the feasibility of activated carbon adsorption process depends on many factors including the feasibility of regeneration and disposal of spent activated carbon. Therefore, the spent activated carbon 